Gut, 1969, 10, 85-90

\title{
The coeliac axis and its branches in splenomegaly and liver disease
}

\author{
LAURENCE BLENDIS, LOUIS KREEL, AND ROGER WILLIAMS \\ From the M.R.C. Group on Metabolism and Haemodynamics of Liver Disease, King's College Hospital, \\ and the Royal Free Hospital, London
}

The anatomy of the coeliac axis and superior mesenteric artery was carefully defined by dissection (Michels, 1955) but this knowledge assumed major importance with the advent of selective catheterization for visualizing in detail the liver, spleen, and pancreas (Ödman, 1956 and 1958). Since these initial studies selective arteriography has become a well recognized diagnostic procedure in pancreatic disease (Lunderquist, 1965), hepatic tumours (Stulberg and Bierman, 1965; Kreel, 1968), in demonstrating the portal vein (Boijsen), Ekman, and Olin, 1963; Kreel and Williams, 1964), and in various splenic conditions (Rosch, 1966). The radiological signs in these various conditions have been summarized in a comprehensive study based on more than 900 cases by Sammons, Neal, Armstrong, and Hager (1967). The value of hepatic arteriography has also been shown in the recognition of characteristic arterial patterns in cirrhosis (Acker, Galambos, and Weens, 1964).

There has, however, been little attempt at exact correlation of the comparative sizes of the coeliac axis and splenic and hepatic arteries in relation to the size of the spleen in these diseases. In this paper we present such an analysis in a series of 161 selective coeliac arteriograms. The relationship between the changes in vascular size and splenic blood flow in a selected group is also described.

\section{MATERIAL AND METHODS}

The 161 patients forming this series were divided into various clinical groups, the age ranges of which were between 20 and 80 years. The control group of 48 patients was investigated by aortography or selective arteriography for the presence of renal or pancreatic disease, retroperitoneal disorders, or for abdominal pain of uncertain origin. A further 28 patients, who had systemic hypertension, were similarly investigated.

Thirty-two of the patients with cirrhosis had cryptogenic, alcoholic, or primary biliary cirrhosis. Of the remainder, two had chronic active hepatitis, two haemochromatosis, and one the Budd Chiari syndrome. Four patients had extrahepatic portal vein thrombosis and one idiopathic portal hypertension (Williams, Condon, Williams, Blendis, and Kreel, 1968). In addition there were nine cirrhotic patients with portacaval shunts, in all of whom the anastomosis was shown to be patent by splenic venography.

Fourteen patients had hepatic tumours. Eight had primary hepatomas (four with preexisting cirrhosis), two a primary cholangioma, three multiple metastatic deposits, and one multiple benign haemangiomata.

Fifteen patients suffering from tropical splenomegaly were studied in Uganda (Williams, Parsonson, Somers, and Hamilton, 1966). There were five patients with blood dyscrasias, including two with congenital spherocytosis and one of each with congenital elliptocytosis, chronic myeloid leukaemia, and myelofibrosis. One patient had Gaucher's disease.

MEASUREMENTS Selective coeliac arteriography was performed as previously described (Kreel and Williams, 1964), with a focal film distance of $100 \mathrm{~cm}$ giving a constant magnification factor of $10 \%$. The maximum width of the coeliac axis was measured, as well as that of the splenic and hepatic arteries taken at a point immediately beyond their origins. The length of the splenic artery was taken from its point of origin to the first major bifurcation at the splenic hilum. The number and size of the arterial branches within the spleen were graded from + to +++ .

Splenic area $\left(\mathrm{cm}^{2}\right)$ was measured from an anteroposterior angiographic film showing the clearest outline and used as an index of spleen size (Blendis, Kreel, and Williams, 1969). In 15 patients spleen weight was also obtained after splenectomy or at necropsy, care having been taken to clamp the splenic artery and vein simultaneously. Splenic blood flow in millilitres per $100 \mathrm{~g}$ per minute was measured in 55 patients at the same time as arteriography, using the radioxenon technique (Williams et al, 1968). In the 15 patients in whom spleen weight became known total spleen flow was also calculated.

\section{RESULTS}

COELIAC AXIS The mean width of the coeliac axis in the control patients was $0.9 \mathrm{~cm}$ (range 0.7 to 1.1 $\mathrm{cm})$, the patients with essential hypertension having 
identical values. Dilatation of the coeliac axis was found in patients with cirrhosis (mean 1.1 , range 0.8 to $1.6 \mathrm{~cm}$ ), with a portacaval anastomosis (mean 1.2 , range 0.9 to $1.5 \mathrm{~cm}$ ) and with tropical splenomegaly (mean 1.1 , range 0.7 to $1.5 \mathrm{~cm}$ ). The coeliac axis was also dilated (mean $1.1 \mathrm{~cm}$ ) in three of the four patients with portal vein thrombosis and in seven of 14 with hepatic tumours (mean width 1.2 $\mathrm{cm}$, range 0.8 to $1.5 \mathrm{~cm}$ ). In two patients with blood dyscrasias where the coeliac axis was shown the vessel was dilated to $1 \cdot 1$ and $1 \cdot 2 \mathrm{~cm}$.

HEPATIC ARTERY The mean width $(0.6 \mathrm{~cm})$ and range of values $(0.4$ to $0.8 \mathrm{~cm})$ in the control patients and in those with essential hypertension were identical (Fig. 1). In cirrhosis and tropical

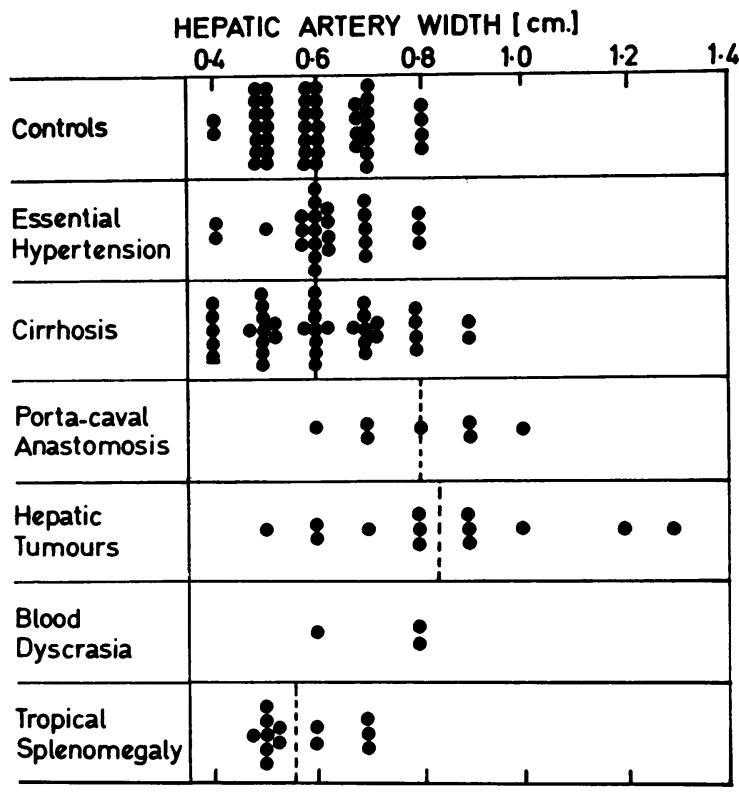

FIG. 1. The hepatic artery width in the different clinical groups studied with the mean values shown.

splenomegaly there was no evidence of hepatic artery dilatation, and in all four patients with portal vein thrombosis the hepatic artery calibre was at the lower limit of normal. The mean width of the hepatic artery in patients with a portacaval anastomosis was $0.8 \mathrm{~cm}$ (range 0.6 to $1.0 \mathrm{~cm}$ ) which was significantly greater than the mean of the unoperated group (n 44, t $3.73 \mathrm{P}<0.01$ ). The hepatic artery was also dilated in six of the patients with hepatic tumours, the mean width $0.8 \mathrm{~cm}$, being significantly greater than that of the control group (n 55, t 3.3, P < 0.01).
SPLENIC ARTERY A number of patients with systemic hypertension had wider splenic arteries than those of the control patients although the

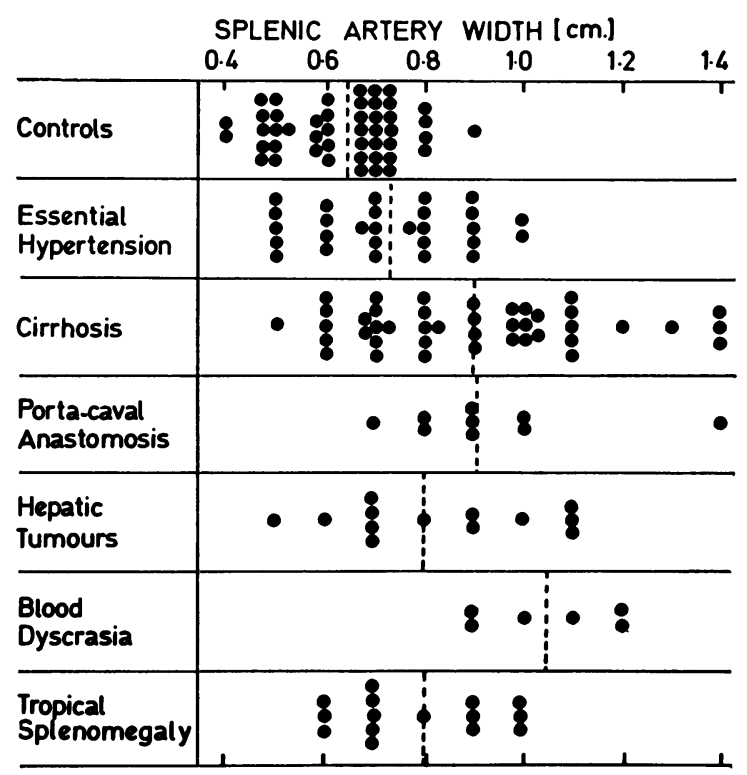

FIG. 2. The splenic artery width in the different clinical groups studied with the mean values shown.

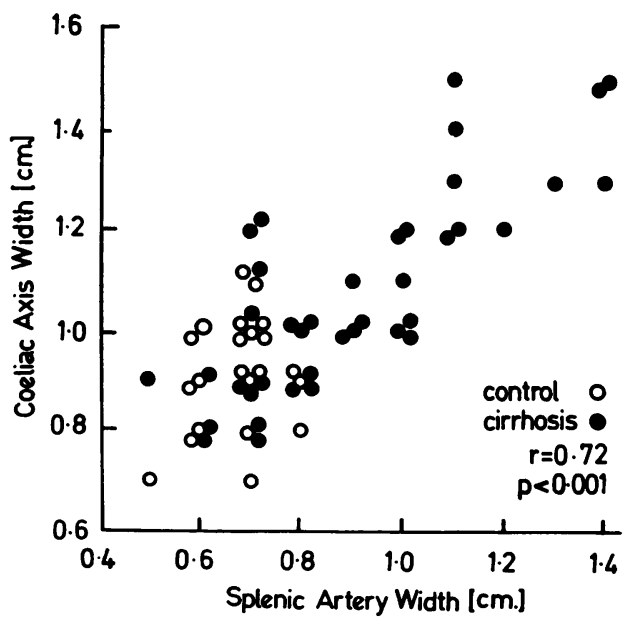

FIG. 3. The relation of the coeliac axis width to splenic artery width in control patients and patients with cirrhosis.

difference between the means of the two groups was not significant (Fig. 2). Significant increases in mean width as compared with the control group were found in the cirrhotics ( $\mathrm{88}, \mathrm{t} \mathrm{4.28,} \mathrm{P}<0.001$ ) and in patients with portacaval anastomosis (n 56, t 3.55 $P<0.01)$. The mean and range of values in the 
patients with portacaval anastomosis were similar to the non-shunted group, and if $0.8 \mathrm{~cm}$ is taken as the upper limit of normal (mean $+2 \mathrm{SD}$ ) the splenic artery width was increased in $66 \%$ and $50 \%$ of these patients respectively. The splenic artery was dilated (mean $1.0 \mathrm{~cm}$ ) in all four patients with portal vein thrombosis. Of the 14 patients with hepatic tumours the splenic artery width was increased in the six with the most vascular tumours (Fig. 2).

There was a significant correlation between the splenic artery width and the hepatic artery width in the control patients (r. 37, P $<0.02$ ) but in the cirrhotic patients the splenic artery was dilated in the absence of any change in the hepatic artery. Variations in the width of the coeliac axis followed pari passu with those of the splenic artery both in the control and cirrhotic groups of patients, the association being highly significant (Fig. 3).

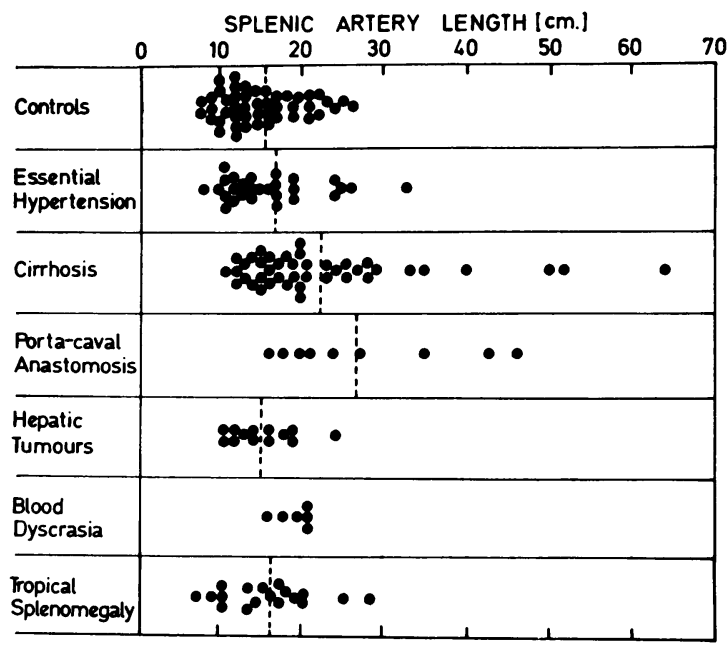

FIG. 4. The splenic artery length in the different clinical groups with the mean values shown.

The only significant changes in length of the splenic artery were found in the patients with cirrhosis and in those with a portacaval anastomosis (Fig. 4). The mean and range of values were similar in the two groups and in both there was a significant correlation (r. 68, P <0.001) between the increase in width and length of the artery. In the four patients with portal vein thrombosis splenic artery length was at the upper limit of normal.

Dividing the patients into those above and those below the age of 40 years or into decades revealed no difference in the width or length of the splenic artery in the various age groups. There was also no relation between the width or length of the splenic artery and the sexes or the duration of the history in the diseased group (Table I).

\section{T A B L E I}

LENGTH OF HISTORY RELATED TO CHANGES IN SPLENIC ARTERY WIDTH AND LENGTH IN PATIENTS WITH CIRRHOSIS

\begin{tabular}{rlll}
$\begin{array}{l}\text { Length of } \\
\text { History } \\
(y r)\end{array}$ & $\begin{array}{l}\text { No. of } \\
\text { Patients }\end{array}$ & $\begin{array}{l}\text { Mean } \\
\text { Width } \\
(\mathrm{cm})\end{array}$ & $\begin{array}{l}\text { Mean } \\
\text { Length } \\
(\mathrm{cm})\end{array}$ \\
\hline $0-5$ & 12 & 0.92 & $24 \cdot 8$ \\
$5-10$ & 9 & $0 \cdot 8$ & $20 \cdot 9$ \\
$10-20$ & 9 & 0.93 & $20 \cdot 2$
\end{tabular}

RELATION OF COELIAC AXIS AND ITS BRANCHES TO SPLEEN SIZE AND BLOOD FLOW The mean splenic area in the control group was $94 \mathrm{~cm}^{2}$ (SD $19 \mathrm{~cm}^{2}$ ). The corresponding values in the patients with essential hypertension were similar (mean 99 SD 16

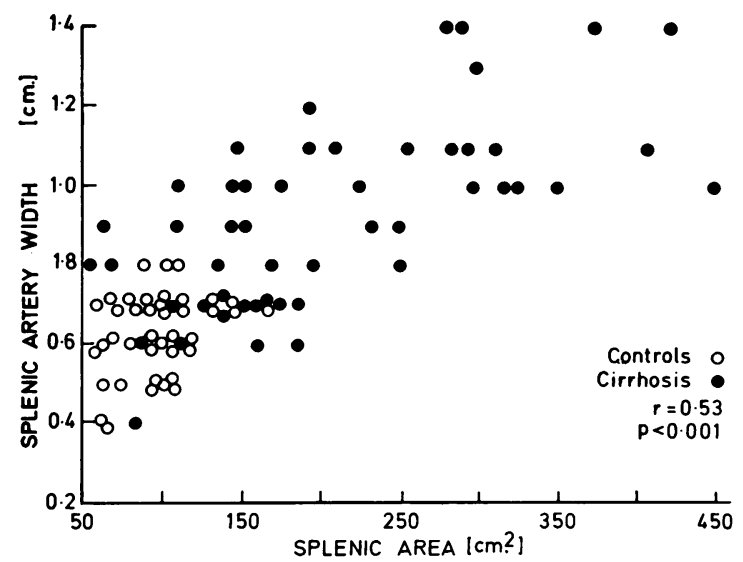

FIG. 5. The relation of splenic artery width to splenic area in control patients and in patients with cirrhosis.

$\mathrm{cm}^{2}$ ). In the cirrhotic patients and in those with portal vein thrombosis splenic area varied widely from 80 to $417 \mathrm{~cm}^{2}$ but was within the normal range in eight of the nine patients with a portacaval shunt. The majority of patients with tropical splenomegaly had enormously enlarged spleens (mean 325 SD $80 \mathrm{~cm}^{2}$ ). There was a close correlation between the width of the splenic artery and the splenic area in cirrhotic and control patients (Fig. 5) but there was no such relation between area and the length of splenic artery the width of the hepatic artery, or the coeliac axis.

In five of the 13 patients with hepatic tumours splenic area was increased $\left(143\right.$ to $\left.280 \mathrm{~cm}^{2}\right)$. In two 
of these there was underlying cirrhosis and one was shown at necropsy to have glands in the porta hepatis which may have caused portal hypertension. The other two patients had highly vascular hepatic tumours. However, the size of the spleen did not correlate with dilatation of the splenic artery.

Spleen blood flow per $100 \mathrm{~g}$ tissue was reduced in 21 patients with cirrhosis, with a mean value of $70 \mathrm{ml}$ per $100 \mathrm{~g}$ per min compared with $96 \mathrm{ml}$ per $100 \mathrm{~g}$ per min in controls (Williams et al, 1968). It was possible to calculate total blood flows in eight patients with cirrhosis, one with portal vein block, and four with blood dyscrasias. Values ranged from 400 to $910 \mathrm{ml}$ per min as compared with one control patient with a blood flow of $154 \mathrm{ml}$ per minute. When these 14 patients were grouped together the total spleen blood flow was closely correlated to the width of the splenic artery (r. 7, P <0.01), whereas a statistically significant correlation could not be demonstrated in patients with tropical splenomegaly (Fig. 6). Total flow was also signi-

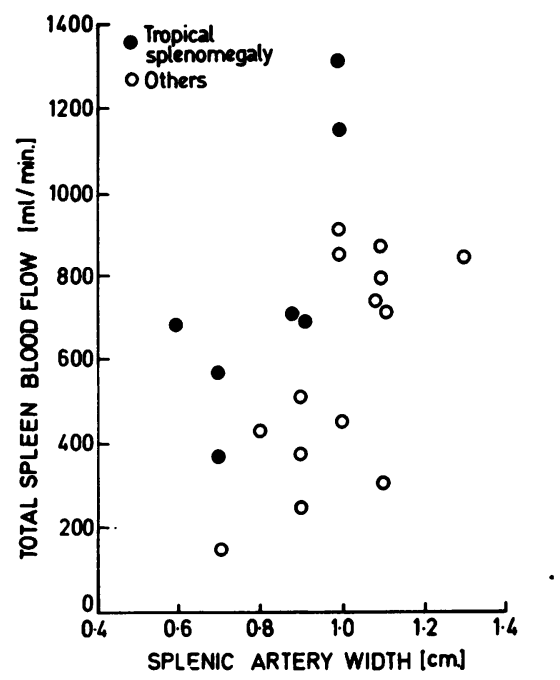

FIG. 6. Splenic artery width related to total spleen blood flow in patients with various disorders and in tropical splenomegaly.

ficantly related to the splenic area (r. 6, $\mathrm{P}<0.02)$. Patients with cirrhosis and raised total blood flow also appeared to have increased vascularity of the splenic pulp with prominent, dilated peripheral vessels.

One patient with cirrhosis and one with idiopathic portal hypertension were studied before and after a portacaval anastomosis. In the cirrhotic patient there was a decrease in spleen size from 172 to $109 \mathrm{~cm}^{2}$ associated with a rise in spleen blood flow from 71 to $113 \mathrm{ml} / 100 \mathrm{~g} /$ minute. Approximate total splenic blood flows before and after operation calculated from a regression equation relating size to weight (Blendis, Williams, and Kreel, 1969) were 320 and $340 \mathrm{ml} / \mathrm{minute}$. In the second patient the spleen area decreased from 417 to $368 \mathrm{~cm}^{2}$ which was associated with a drop in the estimated total splenic blood flow from 1,500 to $1,250 \mathrm{ml} /$ minute. There was no change in the width of the coeliac axis or splenic artery in either patient. Unfortunately, the hepatic artery was not visualized on each occasion, making comparison impossible.

\section{DISCUSSION}

The present findings show that the increase in the width of the coeliac axis in cirrhotic patients was closely related to the increased width of the splenic artery which in turn was related to enlargement of, and increased blood flow through, the spleen. The increased size of the spleen, which in cirrhosis and tropical splenomegaly is due partly to venous engorgement and partly to reticulo-enthothelial cell hyperplasia (McMichael, 1934; Moschcowitz, 1948; Pryor, 1967), is accompanied by an increased total blood supply, although flow per $100 \mathrm{~g}$ tissue is often reduced (Williams et al, 1966, 1968). An increase in blood flow cannot occur without dilatation of the entire splenic arterial tree (Pouseille's law) and in keeping with this are the studies of Manenti and Williams (1966), using injected spleen casts, which showed an increased number of peripheral arterioles of $100 \mathrm{~mm}$ diameter. In addition to local factors circulating vasodilator substances may sometimes have an additional effect. The cardiac output is often raised (Even, Nicollo, Benhamou, and Fauvert, 1965), the blood flow through skin and muscle is also increased (Kontos, Shapiro, Mauck, and Patterson, 1964), and there is evidence of an increased number of small peripheral arterioles in the lungs (Berthelot, Walker, Sherlock, and Reid, 1966). All these findings show that a generalized vasodilatation may occur in some patients with cirrhosis.

Increasing tortuosity of peripheral vessels is a well-known accompaniment of aging but in the cirrhotic patients there was no relationship between tortuosity and either age or length of history. The increased length and tortuosity of the splenic artery is probably a secondary effect of arterial dilatation, although there was no direct relationship either to total splenic blood flow or size of the spleen. This was particularly striking in patients with tropical splenomegaly who had enormously enlarged spleens, increased blood flows, but splenic arteries of normal length. 
The absence of any change in splenic artery calibre following portacaval anastomosis with resultant decrease in spleen size may be explained by the finding that although flow per $100 \mathrm{~g}$ of tissue increases, total blood flow may remain unchanged. In addition, irreversible histological changes, particularly within the elastic layer of the splenic artery wall, may have taken place. As further evidence of this change it is to be noted that peripheral aneurysms of the splenic artery were present in four of the nine patients with portacaval shunts and in seven of the 42 patients with cirrhosis. These aneurysms were characteristically found at arterial bifurcations within the substance of the spleen (Kreel, 1967; Williams, Kreel, and Blendis, 1967). Although aneurysms of the main splenic artery are common in the elderly, particularly in women, in whom they can be found in 10 to $20 \%$ of cases (Bedford and Lodge, 1960; Kreel, 1967) intrasplenic aneurysms are rarely found.

The use of the splenic area as a measure of splenic size may be questioned. McFadzean and Todd (1967) have shown that the spleen may shrink during removal even when care is taken to apply both arterial and venous clamps simultaneously. However, we have found a close relationship between the area of an anteroposterior radiograph at standard magnification and the weight of the spleen both in a series of patients coming to splenectomy and in a larger group in which the spleen was weighed at necropsy (Blendis, Williams, and Kreel, 1969).

There are conflicting opinions as to the exact change in the hepatic artery in cirrhosis. Ödman (1958) found enlargement of the hepatic artery only in some patients with cirrhosis, this being related to an increase in size of the liver, whereas Boijsen and his colleagues (1963) concluded that this artery was generally enlarged. Similarly in necropsy injection studies MacIndoe (1928) described enlargement of the hepatic artery as being inconsistent whereas Hales, Allan, and Hall (1959) found it in every case. In the present series no dilatation of the hepatic artery could be demonstrated in non-shunted patients with cirrhosis. However, dilatation of the hepatic artery was seen in three out of seven patients with a portacaval anastomosis. This is in agreement with experimental studies of Restrepo and Warren (1962) showing that hepatic arterial blood flow often increases following this operation. It was surprising, therefore, that in the four patients with an extrahepatic portal vein thrombosis and large venous collateral channels, which, functionally should be identical to a portacaval anastomosis, the hepatic artery was in the low normal range.

In agreement with previous authors (Milanés,
McCook, and Hernandez, 1953; Baum, Roy, Finkelstein, and Blakemore, 1965) we have demonstrated that the presence of vascular hepatic neoplasms is usually accompanied by dilatation of the hepatic artery. Hepatic neoplasms, whether primary or secondary, are predominantly supplied by hepatic artery radicles (Wright, 1937; Breedis and Young, 1954). In relatively avascular tumours hepatic artery blood flow and width may remain normal. Benign haemangiomata of the liver have a portal as well as an arterial blood supply (Breedis and Young, 1954), and in our patient in whom the width of the hepatic artery was normal and the splenic artery dilated, there may have been a relatively small increase in hepatic arterial blood flow, compared with portal blood flow. Little attention has been paid to changes in the size of the splenic artery or spleen in patients with hepatic tumours. The enlargement of the spleen and dilatation of the splenic artery found in two of our patients in the absence of cirrhosis or portal vein thrombosis may be a reflexion of increased blood flow through the spleen caused by the increased demand for portal blood by tumour tissue.

\section{SUMMARY}

An analysis of 161 selective coeliac arteriograms showed that variations in the width of the coeliac axis in cirrhosis were closely related to changes in the splenic artery. The splenic artery was significantly dilated in patients with portal hypertension and in those patients with a portacaval anastomosis. There was a close correlation between splenic artery dilatation and total splenic blood flow, the latter being correlated with increased splenic size.

Dilatation of the main hepatic artery was not found in cirrhosis although it was a common finding in patients with portacaval anastomosis or a hepatic tumour. Splenic enlargement and dilatation of the splenic artery were found in patients with vascular hepatic tumours, possibly related to increased portal blood flow.

We are grateful to Professor Sheila Sherlock for her encouragement in the early part of this work, to P. J. S. Hamilton for assistance with studies in the Uganda patients, and to King's College Hospital Research Fund for financial support.

\section{REFERENCES}

Acker, J. J., Galambos, J. T., and Weens, H. S. (1964). Selective coeliac angiography. Amer. J. Med., 37, 417-423.

Baum, S., Roy, R., Finkelstein, A. K., and Blakemore, W. S. (1965). Clinical applications of selective celiac and superior mesenteric arteriography. Radiology, 84, 279-295.

Bedford, P. D., and Lodge, B. (1960). Aneurysm of the splenic artery. Gut, 1, 312-320. 
Berthelot, P., Walker, J. G., Sherlock, S., and Reid, L. (1966). Arterial changes in the lungs in cirrhosis of the liver-lung spider naevi. New Engl. J. Med., 274, 291-298.

Blendis, L. M., Williams, R., and Kreel, L. The relation of splenic area to splenic weight. Gut in press.

Boijsen, E., Ekman, C. A., and Olin, T. (1963). Coeliac and superior mesenteric angiography in portal hypertension. Acta chir. scand., 126, 315-325.

Breedis, C., and Young, G. (1954). The blood supply of neoplasms in the liver. Amer. J. Path., 30, 969-985.

Even, P. H., Nicollo, F., Benhamou, J. P., and Fauvert, R. (1965). Le débit cardiaque au cours des maladies du foie. Effets de l'anastomose porto-cave et des diurétiques. Rev. franç. Etud. clin. biol., 10, 799-814.

Hales, M. R., Allan, J. S., and Hall, E. M. (1959). Injection-corrosion studies of normal cirrhotic livers. Amer. J. Path. 35, 909-941.

Kontos, H. A., Shapiro, W., Mauck, H. P., and Patterson, J. L., Jr (1964). General and regional circulatory alterations in cirrhosis of the liver. Amer. J. Med., 37, 526-535.

Kreel, L. (1967). The recognition and incidence of splenic artery aneurysms. M.D. Thesis, University of Witwatersrand.

- (1968). Arteriography in the diagnosis of abdominal disease. In Progress in Clinical Surgery, Series III. Edited by R. Smith, Churchill, London.

-, and Williams, R. (1964). Arteriovenography of the portal system. Brit. med. J., 11, 1,500-1,503.

Lunderquist, A. (1965). Angiography in carcinoma of the pancreas. Acta radiol. (Stockh.), suppl. 235.

McFadzean, A. J. S., and Todd, D. (1967). The blood volume in postnecrotic cirrhosis of the liver with splenomegaly. Clin. Sci. 32, 339-350.

MacIndoe, A. H. (1928). Vascular lesions of portal cirrhosis. Arch. Path., 5, 23-42.

McMichael, J. (1934). The pathology of hepatolienal fibrosis. J. Path. Bact., 39, 481-502.

Manenti, F., and Williams, R. (1966). Injection studies of the splenic vasculature in portal hypertension. Gut, 7, 175-180.
Michels, N. A. (1955). Blood Supply and Anatomy of the Upper Abdominal Organs. Lippincott, Philadelphia.

Milanés, B., McCook, J., and Hernandez, A. L. (1953). Aortography and tumors of the liver. Angiology, 4, 312-320.

Moschcowitz, E. (1948). The pathogenesis of splenomegaly in hypertension of the portal circulation: 'congestive splenomegaly'. Medicine (Baltimore), 27, 187-221.

Ödman, P. (1956). Percutaneous selective angiography of the main branches of the aorta: preliminary report. Acta radiol. (Stockh.), 45, 1-14.

(1958). Percutaneous selective angiography of the coeliac artery. Ibid., suppl., 159.

Pryor, D. S. (1967). Splenectomy in tropical splenomegaly. Brit. med. J., 11, 825-828.

Restrepo, J. E., and Warren, W. D. (1962). Total liver blood flow after portocaval shunts, hepatic artery ligation and 70 per cent hepatectomy. Ann. Surg., 156, 719-726.

Rosch, J. (1966). Tumours of the spleen. The value of selective arteriography. Clin. Radiol., 17, 183-190.

Sammons, B. P., Neal, M. P., Jr, Armstrong, R. H., Jr, and Hager, H. G. (1967). Ten years experience with celiac and upper abdominal superior mesenteric arteriography. Amer. J. Roentgenol. $101,345-360$.

Stulberg, J. H., and Bierman, H. R. (1965). Selective hepatic arteriography. Radiology, 85, 46-55.

Williams, R., Parsonson, A., Somers, K., and Hamilton, P. J. S. (1966). Portal hypertension in idiopathic tropical splenomegaly. Lancet, 1, 329-333.

_- Kreel, L., and Blendis, L. M. (1967). Coeliac axis catheterisation; uses and value in portal hypertension. In The Liver, pp. 125-135. Edited. by A. E. Read. Butterworth, London.

-, Condon, R. E., Williams, H. S., Blendis, L. M., and Kreel, L. (1968). Splenic blood flow in cirrhosis and portal hypertension. Clin. Sci., 34, 441-452.

Wright, R. D. (1937). The blood supply of newly developed epithelial tissue in the liver. J. Path. Bact., 45, 405-414. 